\title{
Retooling GSM-based Services to Link Rural Farmers with Knowledge Experts
}

\author{
Paul G. Garcia Jr., Thelma D. Palaoag
}

\begin{abstract}
Information is one of the most important elements that support the agriculture industry today. ICT-based information systems such as social media, websites, multimedia, mobile apps and other technology driven initiatives were initiated by organizations to disseminate knowledge products. However, with most third world country's poor ICT infrastructure furthered by the involvement of technology deprived users, an ICT tool to share information has to be chosen well noting its availability, applicability and practicality for the common end-users. This quantitative research explores and establishes the use of GSM-based services for its potential role as an alternative communication and information sharing/access tool for both rural farmers and knowledge experts such as the academe. It is a fact that basic or traditional way of texting and voice calls have been in use in the past decade as communication tool. However, this study's aim is to establish a theoretical GSM-based model framework that integrates new technological and management features to upscale this service thus, the term "retooling". The result of this study will be the basis of the actual implementation of the framework as the succeeding part of this study. This paper's output can be used as guide for researchers, academicians, extension service workers, project managers as well as organizations planning to offer similar technology-based services in various fields.
\end{abstract}

Keywords : Mobile agriculture, short messaging system, SMS, GSM-based service, ICT

\section{INTRODUCTION}

Information on the management of crops, pests and diseases, harvest, marketing, fertilizers, other farm inputs, as well as price, weather alerts and transportation are some of the things most sought by farmers. As knowledge experts $(\mathrm{KE})$, it is a challenge for the academe and concerned agencies to disseminate such information to the remote farmers, as well as farmers have difficulty accessing such information as input to their farming practice [1]. For this study, the KEs refer to the developers of agri-based knowledge while the farmers are the end-users or consumers of such knowledge. While there are lots of ICT-based tools to communicate information, global system for mobile (GSM) communication which provides short messaging system (SMS) or texting and voice call has become popular.

Interestingly, farmers are among the subscribers relying on cellphones for their communication and information access/sharing needs. It is fascinating to note that mobile

Revised Manuscript Received on January 2, 2020.

* Correspondence Author

Paul G. Garcia Jr.*, Information and Communications Technology Office, Benguet State University, La Trinidad, Benguet, Philippines. Email: p.garciajr@bsu.edu.ph

Thelma D. Palaoag, College of Information Technology and Computer Science, University of the Cordilleras, Baguio City, Philippines. Email: tpalaoag@gmail.com phones are capable to share and exchange knowledge and ideas [2] for the agriculture industry.

Philippines is an agriculture country with 11.29 million of the 38.74 million workers employed in the agriculture sector [3]. Cordillera Administrative Region (CAR), the locale of this study has most of its population at $51.9 \%$ or 365,000 out of 759,000 employed in agriculture especially in vegetable production. The CAR, having temperate climate is producing more than $83 \%(262,283$ metric tons) of major highland agricultural crops such as cabbage, carrots and potatoes among others [4] making it the "salad bowl" of the country. It is the major vegetable producer that supplies markets in Metro Manila, neighboring provinces including the Visayas and the Mindanao islands.

Meanwhile, explosive growth for cellphone service in the Philippines have reached 130,319,459 subscriptions, thus gaining the branding "texting capital of the world" by the media. Interestingly, farmers are among the subscribers relying on cellphones for their communication and information access/sharing needs. It is worthwhile to note that global system for mobile (GSM) service as practical, cheap, and highly available technology to share and exchange knowledge and ideas [2,5-6] for the agriculture industry especially in the remote areas.

This study aimed to find out how GSM-based technology could be retooled and utilized by agricultural practitioners in the Philippines particularly in the Cordillera Administrative Region (CAR).

\section{A. GSM Infrastructure}

GSM is an international standard for mobile networks to transmit voice and data between digital cellular phones and other mobile devices in wireless infrastructure using open and digital cellular technology in frequencies $850 \mathrm{MHz}$, $900 \mathrm{MHz}, 1800 \mathrm{MHz}$ and $1900 \mathrm{Mhz}$. GSM services include voice calls, short messaging system popularly called texting, and multimedia messaging service (MMS). This technology has become so popular worldwide because of cheap transmission cost. For example, SMS rate is as low as 0.01 USD and call rates at 0.12 USD in the Philippines.

Some interesting developments in GSM services lead to the implementation of cashless mobile payments and fund transfers, security measures through text-based verifications as support to online transaction, automated payment for airtime credits for cellular phones, pull-based SMS messaging systems and others. Also, some SMS and voice services have already been integrated with online information systems and databases providing seamless implementation of text-based communication and interactive voice response (IVR) systems. 


\section{B. Related Work}

With its basic infrastructure, SMS or texting model is used as service[1] for governments. SMS notification as government services is utilized in countries like Lagos State, Nigeria [7]. In Agriculture, this service is perceived to be easy to use, efficient in terms of time and distance, with value for money [8]. Farmers in Indo-Gangetic plains of India access information from other farmers [9] using this method. GSM services are also said to be effective medium for market prices and climate information [10,11]. Other advantages includes easy access to market information which in turn reduces markets and prices search cost [11], it reduces price dispersion [12], and improves the farmer's bargaining power [13]. Alarms and bulletins are sent to farmers in Jamaica [14] with alerts on weather and best agricultural practices.

While young agriculturists get information from the Internet [15], agricultural knowledge sharing and information dissemination should be created in view of the mass communication technology such as mobile systems since phones are generally utilized for communication and sharing knowledge [16]; and further, most rural farmers have access to it [17].

\section{Framework of the Research}

There are two key players in this research. The knowledge experts who produces agri-based knowledge products in the form of information, and the rural farmers as the end-users of the said information. This study establishes the extent on how these two groups utilize GSM services in communication, gathering and sharing information. To establish the data, the demography, extent use of GSM service, perception on the six levels of SMS-based system [5] (Fig. 2), and the perception on fifteen SMS-based e-Government [6] service for both parties were investigated. Being the knowledge producer, the KEs engagement in knowledge sharing is investigated dwelling particularly on their perception on levels and outcome of knowledge sharing, the individual as well as technology barriers of knowledge sharing. For the farmers, their perception on the advantages of the different capabilities of GSM service is included in the study. Along this line, the existing GSM infrastructure, government regulations on communication systems[22-26 RA \& NTC], and the perceived the capabilities of SMS technology model as identified by the United Nations Commission on Human Rights (UNCHR) [21] shall be integrated in the framework (Fig. 1).

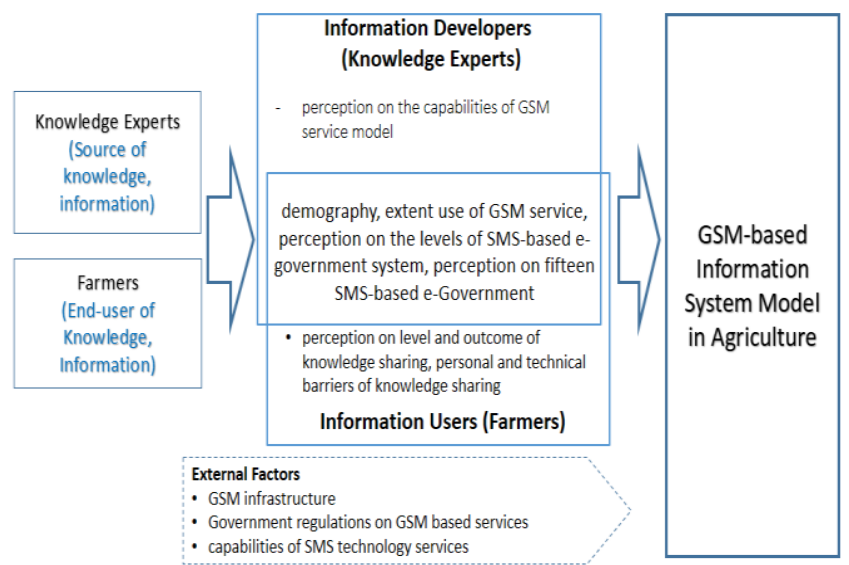

Fig 1. Conceptual framework

\section{METHODOLOGY}

This research is quantitative in nature using unstructured survey for the data gathering process. Respondents involve thirty one (31) agri-based KEs from Benguet State University and Ifugao State University, the two state owned agricultural universities in the region. These KEs are faculty and researchers who are active and involved in production and dissemination of agri-based knowledge products intended for the rural farmers in Benguet, Ifugao, Mt. province and other nearby provinces. There are sixty (60) rural farmer respondents who are the beneficiaries of the said universities. With more than three hundred thousand possible respondents in the region, convenience sampling was used to determine the sample. Online questionnaires were used to gather data from respondents with internet access while offline respondents were given printed questionnaires. Local personnel assisted in administering the questionnaire to the respondents considering their familiarity with the people and language in the area. Informal interviews and observations were likewise conducted to validate results. Spreadsheet was used to gather and process data on which analysis was based.

\section{RESULTS AND DISCUSSIONS}

\section{A. Respondent's Profile}

There were 60 valid responses from farmers representing the different provinces while 31 KEs of varied field expertise in agriculture were received. KEs and farmers confirmed the existence of GSM service in the urban and remote areas being provided by Smart and Globe, the only two telecommunication service providers in the area. All respondents $(100 \%)$ have mobile phones with the financial means to sustain it. They avail promo airtime credit (KEs-78.6\%; farmers-60\%) but are willing to spend more to access or receive information they prefer to receive. Half majority of both respondents do mostly texting (52\%), then by calling (18\%), social media (13\%) and the remaining activities are for internet, gaming, music and radio. This confirms that both parties have the equipment, the capacity and the means to sustain it thus coming up with a GSM based service is very likely possible.

\section{B. Respondent's Perception of Six Levels of SMS e-Government Service}

The graph shows that both farmers and KEs perceived all six levels of SMS-based e-government services [5] are advantageous as a service (figure 2). Farmers regard communication as the most advantageous service (93.55\%) followed evenly by listening and communication (90.33\%), and the least advantageous is transaction since it is likely that GSM based payments is not yet popular in the region; some of these kinds of service are currently being introduced. KEs similarly declare that listening and communication are the most advantageous service (84\%), the least is push-based service $(77.33 \%)$. 


\section{Farmers and KE Perceptions of GSM Service}

Farmers and KEs have almost similar perception in terms of the factors or constructs in considering a GSM-based service. All the 15 constructs have been perceived as positive or beneficial with rating from $56 \%-88 \%$ for farmers and $66 \%-88 \%$ for KEs respectively. The farmers have identified ease of use, efficiency in time and distance, convenience, value for money as the most positive factors (83.88\%) followed by availability of device and infrastructure, self-efficacy, risk to money and risk to user privacy. KEs identified ease of use, efficiency in time and distance, value for money as the most positive factors $(83.88 \%)$ followed by risk to money availability of device and infrastructure, compatibility, and self-efficacy (Fig. 3).

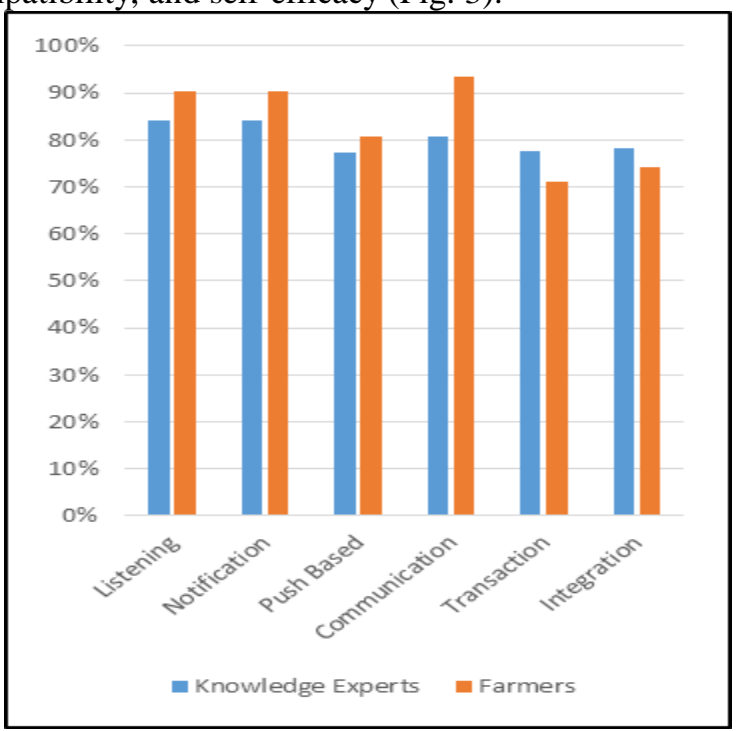

Fig. 2. The six levels of SMS Service as perceived by farmers and KEs

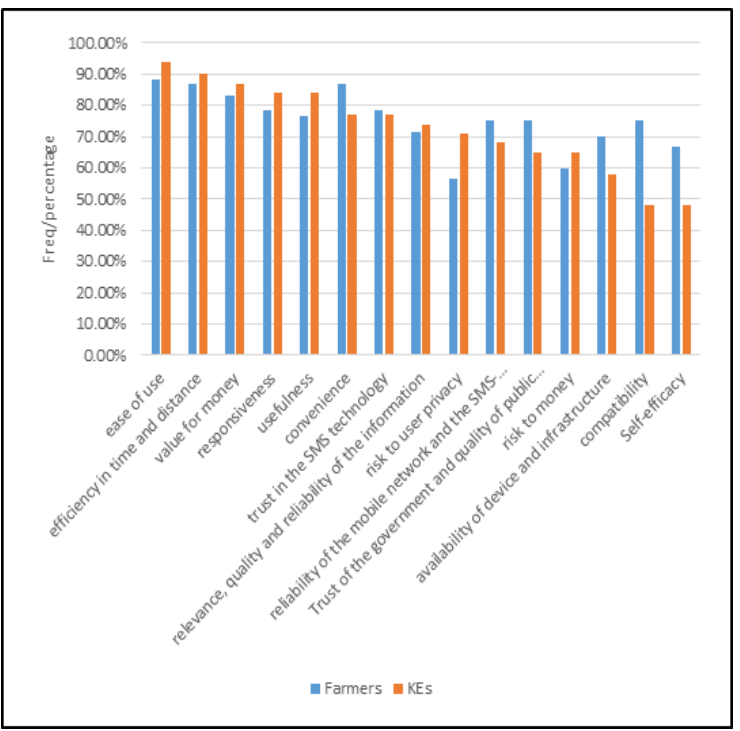

Fig. 3. Farmer's and KE's perception on the capabilities of SMS-based service

\section{Knowledge Experts' Engagement in Knowledge Sharing}

\section{Perception on the Level and Outcome of Knowledge Sharing Engagement.}

With an average agreement of $90.4 \%$, findings reveal that KEs' engagement to knowledge sharing has a positive outcome (Table I). It depicts that they understand the importance of sharing knowledge effectively (94\%) and they know how sharing knowledge benefits them (94\%). Further data analysis through correlation depicts how KEs understand the importance and benefits of knowledge sharing thus increasing their comfortability. KEs are comfortable in doing so due to the strong support of farming community beneficiaries. This confirms that the establishment of support and dedication with stakeholders [18-20] are very important factors in knowledge sharing systems.

Table I: Knowledge expert's Outcome of Knowledge Sharing Engagement

\begin{tabular}{|l|c|c|}
\hline $\begin{array}{l}\text { Outcome of KE Engagement } \\
\text { in Knowledge Sharing }\end{array}$ & Agree & Disagree \\
\hline $\begin{array}{l}\text { 1. KE understand the } \\
\text { importance of sharing } \\
\text { knowledge effectively. }\end{array}$ & $29(94 \%)$ & $2(6 \%)$ \\
\hline $\begin{array}{l}\text { 2. KE know how sharing } \\
\text { knowledge benefits them. }\end{array}$ & $29(94 \%)$ & $2(6 \%)$ \\
\hline $\begin{array}{l}\text { 3. KE can easily share } \\
\text { knowledge. }\end{array}$ & $28(90 \%)$ & $3(10 \%)$ \\
\hline $\begin{array}{l}\text { 4. KE believe that there is a } \\
\text { strong support to sharing } \\
\text { knowledge among KE and } \\
\text { knowledge end-users. }\end{array}$ & $28(90 \%)$ & $3(10 \%)$ \\
\hline $\begin{array}{l}\text { K. KE feel comfortable in } \\
\text { sharing knowledge. }\end{array}$ & $26(84 \%)$ & $5(16 \%)$ \\
\hline
\end{tabular}

KEs Perception on the Individual and Technical Barriers of Knowledge Sharing.

Findings revealed that 9 out of 10 individual barriers for knowledge sharing are critical by almost majority of the respondents (figure 4). Intolerance-to-mistakes-and-not-learning-from-them tops the list while lack-of-trust is in the bottom. The list provides a guide on the list of priorities to address when engaging in knowledge sharing. Pride-of-position-and-authority is a non-critical barrier thus it can be disregarded as barrier. In terms of technical barriers of knowledge sharing, finding reveal that all five constructs are critical and therefore, needs to be addressed before engaging in knowledge sharing (figure 5).The list suggests that mismatch-with-employee's-work-requirement and incompatibility-of-technology are top factors barriers (88\%) to address. Organizations planning to engage in GSM-based services should therefore align staff's functions or roles of knowledge expert in the system, upgrade system to be compatible with new technologies, train and develop staff with new technologies and provide a good technical support for the system. 


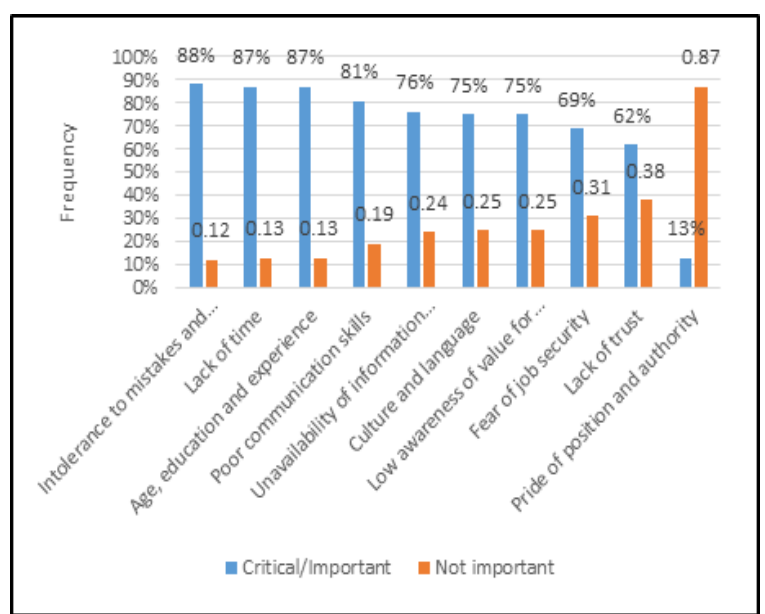

Fig. 4. KE's response for Individual Barriers in knowledge sharing

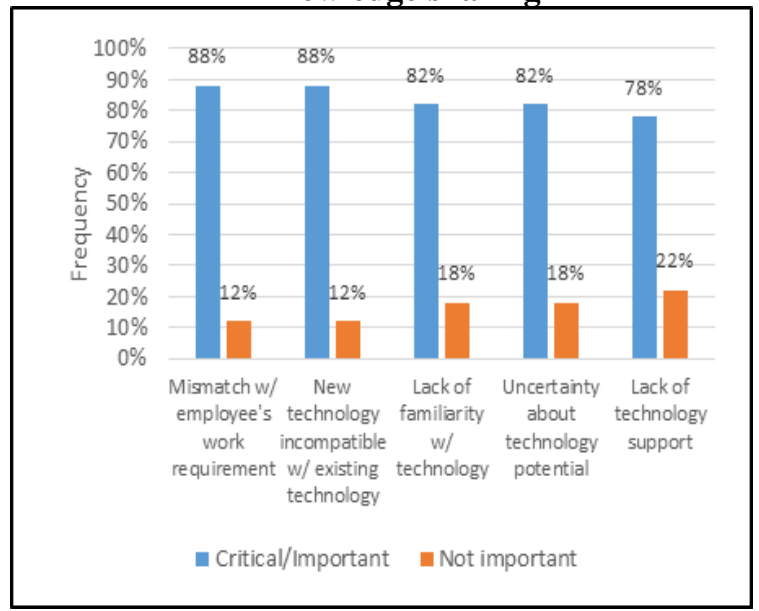

Fig. 5. KE's response for Technology Barriers in knowledge sharing

\section{Developing a GSM-based Knowledge Sharing Model}

Based on the findings on this study, the development of a GSM-based model suggest the following:

1) Integration of the six levels of services [5] in an SMS platform.

a. listen level - where individual can send unformatted SMS inquiries or comments to an SMS platform or service. b. notification level - broadcast SMS messages can be sent to the public as notifications or announcements.

c. pull-based level - individuals can request for a specific information on-demand from the SMS platform.

d. communication level - the SMS platform and individuals can exchange SMS messages using general SMS format;

e. transaction - payment or fund transfer can be integrated in the SMS service;

f. integration level - the system can integrate all several services in one SMS platform). This is the highest level where users' gains more benefit.

This proved that respondents perceived all levels have positive advantage. Transaction level, which involve monetary transactions is already becoming popular in the Philippines thus its potential should be explored. Integration level could come later as it requires several SMS services being integrated together.

2) Integration of the 15 suggested features of SMS system

(Fig. 3). As proven by this paper, the features identified are accepted by the respondents because of their perceived advantages.

3) Integration of the capabilities of an SMS-based service. As a process to retool the GSM-based service, it is suggested that SMS-based services should be able to perform the following: able to send/receive messages to or from anyone, system can be triggered by either a registered or non-registered individual, messages has readily available templates, messages can be personalized, able to send message based on subscriber's location, scheduled message sending, able to conduct polls, can accept messages formats than can be interpreted, provide guided input, miscall trigger, implement skip logic, has a simulation tool before service deployment, collect data on android device, perform interactive voice response, manage contacts, and has data analytics feature. Other features may include use of API and social site integration, use of short codes, text interpretation, advance accounts management, gateway integrations, and others. These capabilities are consolidated features of SMS systems which is suggested by a study commissioned by the United Nations Commission on Human Rights[21]. Some online SMS services can already implement these features thus selecting the proper platform is important. Respondents in this study perceived that all capabilities are advantageous.

4) Capabilities development for knowledge experts - KEs should understand the importance of knowledge sharing and how knowledge sharing can benefit them. KEs should also share knowledge easily and feel comfortable doing it. KEs should also be made to understand the strong support of knowledge end-users in the process.

5) Barriers in knowledge sharing - The 9 individual barriers and 5 technical barriers (figure 3 and 4) should be addressed before engage in knowledge sharing. This is a factor in the success in KS engagement.

6) Strong support from the national government on the implementation and regulation of telecommunication services.

Various telecommunications regulations for each country is presumed to be existent thus its integration to GSM-based service is highly encouraged. For example in the Philippines, The National Telecommunication Commission (NTC) regulates digital telecommunications by protecting the rights of subscribers as well as defining the role of telecommunication service providers [22,23]. It protects subscribers by regulating rates to be affordable for the service [24]. Examples of guidelines based on government regulations are as follows: subscribers should be able to subscribe and unsubscribe from a GSM-based service, subscribers may only receive commercial or advertisements messages after offering consents, incoming SMS or MMS should be free of charge to the subscriber unless the same has opted for the message, broadcast messages from content providers is allowable between 7:00 AM to 9:00 PM except for subscribed services, message sent by service providers shall include the sender/content provider's name, company, 
address and contact numbers. Spamming such as broadcasting text messages to unsuspecting subscribers is now a crime by virtue of Cybercrime Prevention Act of 2012[25] thus be observed and prevented. Subscriber Identification Module (SIM) card registration is another security feature to curb out scam or anonymous messages thus its implementation is highly encouraged.

The figure below (Fig. 6) represents the GSM infrastructure model retooled to implement new technologies. As represented in the image, GSM based applications can be integrated to information systems and databases through internet. Knowledge source uses a managed system to input contents while the information end-users access them through their basic cellular equipment. Meanwhile, SIM can be replaced by an aggregator using short codes or an android phone as relay. SMS gateways are used to send, receive and manage SMS/Voice messages within the platform and through the telecommunication mobile towers.

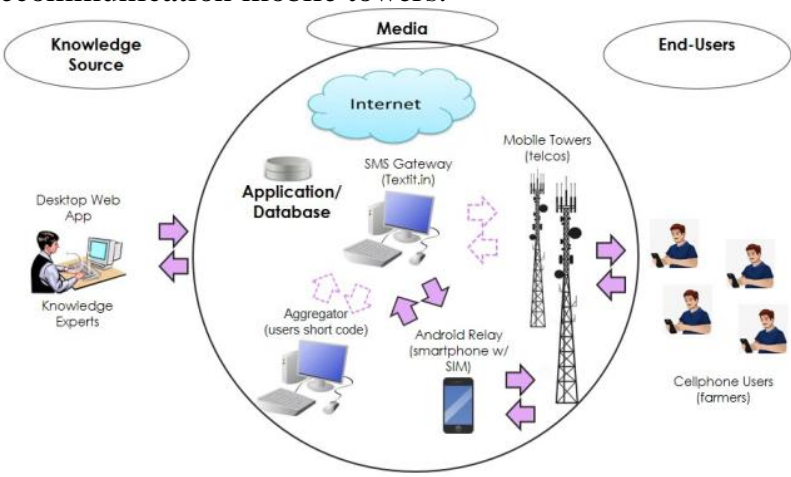

Fig. 6. GSM-based Framework Diagram

\section{CONCLUSION}

GSM services such as texting and calling are being highly utilized by both KEs and farmers. Information technology equipment such as cellphones and its corresponding infrastructure are highly available in urban and remote areas thus becoming a choice of device for communication and information exchange. Cellphones are easy to operate and cheap to acquire and has long lasting power capability making it almost "always on" equipment. Its' potential as a knowledge sharing and communication tool for the agriculture industry can be enhanced more by retooling it with the integration of new GSM technology features and capabilities, capacitating knowledge experts both in technology and knowledge sharing, industry partnerships, and building linkages with the concerned government/non-government agencies such as academe, telecommunication regulating bodies, extension service workers and other concerned agencies. Knowledge sharing and information dissemination should be created in view of the mass communication technology such as mobile systems to be successful.

\section{ACKNOWLEDGMENT}

The contributions, inputs and insights unselfishly provided by people involved in this study are wholeheartedly acknowledged. The Commission on Higher Education (CHED) of the Philippines is likewise appreciated and thanked for the assistance.

\section{REFERENCES}

1. Y. Zhang, L. Wang, and Y. Duan. Agricultural information dissemination using ICTs: A review and analysis of information dissemination models in China. Information Processing in Agriculture. 3, 1 (2016), 17-29.

2. S. Housley, Apple Farmers: How SMS and Mobile Technology Are Shaping Farming; [Online]. Available: [Accessed https://www.notepage.net/learning-center/how-sms-mobile-tech-are-shapi ng-farming.htm, Sharon Housley, ND.]

3. Population and Labor Force, Agricultural Indicators System (AIS), Report no. 2016-9, Philippine Statistics Authority. ISSN-2012-0435, Nov. (2016). [Online]. Available: [Accessed https://psa.gov.ph/sites/default/files/ais_Population_and_labor\%20force2 016F.pdf, 29- March- 2018]

4. D. See, 83 Percent of Crops Produced In Cordillera Baguioheraldexpressonline.com (2016) [Online]. Available: http://baguioheraldexpressonline.com/83-percent-of-crops-produced-in-co rdillera/.

5. T. D. Susanto, R. Goodwin and P. Calder. "A Six-Level Model of SMS-based eGovernment", International Conference on E-Government 2008, Melbourne, ICEG. (2008)

6. T. D. Susanto, and R. Goodwin. "Factors influencing citizen adoption of SMS-based e-government services" [online]. EJEG, vol. 8, pp. 55 - 71. (2010)

7. Chete, F., Oyemade, D., Abere, R., Chiemeke, SC., and Ima-Omasogie, I. Citizens Adoption of SMS Based E-Government Services in Lagos State, Nigeria. Journal of Emerging Trends in Computing and Information Sciences. 3, 4 (2012), 654-660

8. M. Al-ma'aitah, M. Altarwneh, and H. Altarawneh. The State of Using SMS-Based e-Government Services: Case Study in Jordan. International Journal of Advanced Networking and Applications. 4, 3 (2012), 1591-1600.

9. S. Mittal, S. and M. Mehar. Agricultural information networks, information needs and risk management strategies: a survey of farmers in Indo-Gangetic plains of India. Socioeconomics Working Paper 10 Mexico, D.F.: CIMMYT. (2013)

10. F. Laureys, Use of ICT for Agriculture in GIZ projects - Status quo, opportunities and challenges. Deutsche Gesellschaft für Internationale Zusammenarbeit (GIZ) GmbH. (2016)

11. David-West, Olayinka. "Esoko Networks: Facilitating Agriculture Through Technology." GIM Case Study No. B061. New York: United Nations Development Programme, (2010)

12. C. Parker, K. Ramdas, K. and N. Savva. Is IT Enough? Evidence from a Natural Experiment in India's Agriculture Markets. Management Science. 62, 9 (2016), 2481-2503.

13. K. Yovo, Farmer Choice, Cost of Transaction, Bargaining Power and Market Information Services in Togo, American Journal of Economics, Vol. 7 No. 5, (2017), pp. 230-239. doi: 10.5923/j.economics.20170705.04

14. World Bank. ICT in Agriculture: Connecting Smallholders to Knowledge, Networks, and Institutions. Updated Edition. Washington, DC: World Bank. doi:10.1596/978-1-4648-1002-2. (2017)

15. KR. G. Irungu, D. Mbugua, and J. Muia. "Information and Communication Technologies (ICTs) Attract Youth into Profitable Agriculture in Kenya," East African Agricultural and Forestry Journal, vol. 81, pp. 24-33, (2015)

16. D. Peterson. "A survey of Information and Communication Technologies as enablers of knowledge capture and retention in three Southern Africa Development Community (SADC) public broadcasting corporations", South African Journal of Libraries and Information Science, vol. 80, pp. 8 -17 (2014)

17. O. A. Ogbeide and I. Ele. "Smallholder Farmers and Mobile Phone Technology in Sub-Sahara Agriculture," Mayfair Journal of Information and Technology Management in Agriculture vol. 1, pp. 1-19. (2015)

18. A. A. Barakabitze, K. G. Fue and C. A. Sanga, "The Use of Participatory Approaches in Developing ICT-Based Systems for Disseminating Agricultural Knowledge and Information for Farmers in Developing Countries: The Case of Tanzania," The Electronic Journal of Information Systems in Developing Countries, vol. 78, pp. 1-23, (2017)

19. A. Gichamba1, P. W. Wagacha and D. O. Ochieng, "An Assessment of e-Extension Platforms in Kenya," International Journal of Innovative Studies in Sciences and Engineering Technology (IJISSET), vol. 3, pp. 36-40, (2017)

20. L. Z. Manda and R. Chapota, "Integrating radio and e-media in national agricultural policy: the case of agricultural extension and advisory services in Malawi," Journal of Development and Communication Studies, vol. 4. pp. 49-61, (2015) 
21. T. Luge. Comparison of SMS platforms. http://cartong.org/sites/cartong/files/Benchmarking\%20SMS\%20Tools\% 20V\%201.3\%20published.pdf. Accessed: 2018-07-23. (2015)

22. NTC Memorandum Circular 03-03-2005/A, Rules and regulations on broadcast messaging service. http://ntc5.ntc.gov.ph/wp-content/uploads/2017/05/MC-03-03-2005.pdf. Accessed: 2019-06-10. (2005)

23. NTC Memorandum Circular 04-07-2009, Amending Rules and regulations on broadcast messaging service,

http://ntc.gov.ph/wp-content/uploads/2015/10/LawsRulesRegulations/Memo Circulars/MC2009/MC-04-07-2009.pdf. Accessed: 2019-20-10. (2009)

24. Republic Act No. 7925 - "Public Telecommunications Act of the Philippines"

http://www.ombudsman.gov.ph/UNDP4/wp-content/uploads/2013/01/R A7925-Public-Telecommunications-Act.pdf. Accessed: 2019-07-23. (1994)

25. Republic Act No. 10175, S. No. 2796, H. No. 5808, “Cybercrime Prevention Act of 2012", An act defining cybercrime, providing for the prevention, investigation, suppression and the imposition of penalties therefor and for other purposes. Accessed: 2019-08-23. Sept. 12 (2012) G. O. Young, "Synthetic structure of industrial plastics (Book style with paper title and editor)," in Plastics, 2nd ed. vol. 3, J. Peters, Ed. New York: McGraw-Hill, 1964, pp. 15-64.

\section{AUTHORS PROFILE}

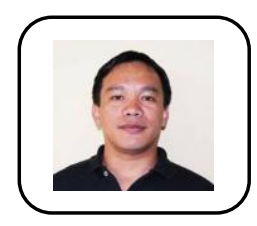

Paul G. Garcia Jr., MCS

Information and Communications Technology Office, Benguet State University, La Trinidad, Benguet, Philippines.

Education:

Master in Computer Science, University of the Cordilleras, Baguio City, Philippines; Doctor in Information Technology (on-going), University of the Cordilleras, Baguio City, Philippines,

Research areas: Mobile agriculture using Global Sytem for Mobile (GSM), Knowledge Management using ICT, Online Learning.

Researches/Publications:

TEXTnology: A Managed SMS Knowledge Sharing for Farmers (ACM),

SMS-Based ICT Tool for Knowledge Sharing in Agriculture (Ei Compendex and Scopus), eLearning Roadmap for Open Distance Learning in Cordillera Administrative Region, Retooling GSM-based Services to Link Rural Farmers with Knowledge Experts, Utilization of Information and Communications Technology for Benguet State University Knowledge Products towards Knowledge Sharing Support for Climate-change Initiatives (unpublished)

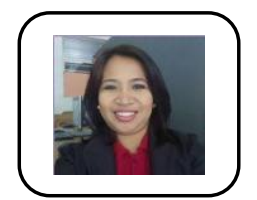

Thelma D. Palaoag, DIT

Department Head/faculty, College of Information Technology and Computer Science, University of the Cordilleras, Baguio City, Philippines

Education:

Master in Computer Science, Doctor in information Technology-University of the Cordilleras, Baguio City, Philippines.

Research areas: Natural language processing, artificial intelligence, intelligent system, data analytics and mining, educational data mining, eLearning, disaster risk management.

Researches/Publications:

Some of the latest researches (2019) includes the following: Improving tourism experience in open data environment with mobile augmented reality: needs and challenges, Environmental acoustic transformation and feature extraction for machine hearing, The sentiments of Philippines' underground artist and technology intervention, Assessing CSU Students' Academic Performance on iLearn Portal Using Data Analytics.

As of 2014, Dr. Palaoag has 43 citations (google scholar), 33 citations (researchgate). 